\title{
Article
}

\section{Zn-P Co-Modified Hierarchical ZSM-5 Zeolites Directly Synthesized via Dry Gel Conversion for Enhanced Methanol to Aromatics Reaction}

\author{
Youhe Wang ${ }^{1, *}$, Zhihong Li $^{1}{ }^{(\mathbb{D}}$, Chang Dai ${ }^{2}$, Ningning Du ${ }^{2}$, Tingting Li $^{2}$, Risheng Wang ${ }^{1}$, Peng Peng ${ }^{2, *(\mathbb{D})}$ and \\ Hongman Sun $1, * \mathbb{D}$ \\ 1 College of Science, China University of Petroleum, Qingdao 266580, China; lizhihong3523@163.com (Z.L.); \\ z18140031@s.upc.edu.cn (R.W.) \\ 2 College of Chemical Engineering, China University of Petroleum, Qingdao 266580, China; \\ 1703010117@s.upc.edu.cn (C.D.); dnn2872984409@163.com (N.D.); lttgongzuoyouxiang@163.com (T.L.) \\ * Correspondence: yhewang@upc.edu.cn (Y.W.); peng.peng@upc.edu.cn (P.P.); \\ hongman.sun@upc.edu.cn (H.S.)
}

check for

updates

Citation: Wang, Y.; Li, Z.; Dai, C.; Du, N.; Li, T.; Wang, R.; Peng, P.; Sun, H. Zn-P Co-Modified Hierarchical ZSM-5 Zeolites Directly Synthesized via Dry Gel Conversion for Enhanced Methanol to Aromatics Reaction. Catalysts 2021, 11, 1388. https:// doi.org/10.3390/catal11111388

Academic Editor: Narendra Kumar

Received: 23 October 2021

Accepted: 15 November 2021

Published: 17 November 2021

Publisher's Note: MDPI stays neutral with regard to jurisdictional claims in published maps and institutional affiliations.

Copyright: (c) 2021 by the authors. Licensee MDPI, Basel, Switzerland. This article is an open access article distributed under the terms and conditions of the Creative Commons Attribution (CC BY) license (https:/ / creativecommons.org/licenses/by/ $4.0 /)$.

\begin{abstract}
A unique method to prepare Zn-P co-modified hierarchical ZSM-5 zeolites was developed. The ZSM-5 zeolite was directly synthesized by a dry gel conversion without adding any templates or seeds. Afterwards, the hierarchical structure was endowed to the ZSM- 5 zeolite by the sequential desilication-dealumination. Zn and P species were then introduced into the hierarchical ZSM5 zeolites by the impregnation method and their activity in methanol to aromatics process was investigated. It was found that the Zn-P co-modified hierarchical ZSM-5 zeolites possessed more Znrelated Lewis acid sites, and the ratio of $\mathrm{Zn}(\mathrm{OH})^{+} / \mathrm{ZnO}$ was increased. The catalytic evaluation results revealed that the benzene, toluene and xylene (BTX) and aromatics selectivity were significantly improved from $20.59 \%$ and $29.41 \%$ of pristine ZSM-5 zeolite to $28.12 \%$ and $41.88 \%$ of Zn-P comodified hierarchical counterpart (1.5Zn0.3P/HZSM-5), respectively. Owing to the introduced highly stable Zn-P co-modified hierarchical structures, the lifetime (conversion not less than 99\%) of ZSM-5 zeolite during methanol to aromatics reaction was increased from $6 \mathrm{~h}$ to $18 \mathrm{~h}$.
\end{abstract}

Keywords: methanol to aromatics; hierarchical ZSM-5; dry gel conversion; Zn-P co-modified

\section{Introduction}

During the past decade, market demand for aromatics, especially benzene (B), toluene $(\mathrm{T})$ and xylene $(\mathrm{X})$, has surged due to the growth of the polymer and fine chemical industries [1]. Thanks to the wide range of non-petroleum origins of methanol including coal, biomass and natural gas, the methanol to aromatics (MTA) process has been successfully developed as a promising source for enlarging aromatics supply [2]. Owing to the suitable acidity and shape-selective generated from the unique framework structures, ZSM-5 (MFI topology) zeolite has attracted extensive attention as the catalyst for methanol to aromatics [3].

ZSM-5 zeolites are typically synthesized by the hydrothermal method in the presence of ammonium-related organic templates [3,4]. However, the high cost and environmental pollution of ammonium-related organic templates during their thermal decomposition are the limiting problems for the synthesis of ZSM-5 at industrial scale [4,5]. Alternatively, a dry gel conversion (DGC) method, which generates high zeolite yield and low environmental pollution [6,7], is regarded as a green, cheap and efficient synthesis route. Xiao et al. reported a combined strategy of both organotemplate- and solvent-free conditions to synthesize aluminosilicate zeolites Beta and ZSM-5 [8,9]. However, usage of the mineralizing agent such as $\mathrm{NH}_{4} \mathrm{~F}$ or $\mathrm{NH}_{4} \mathrm{Cl}$ limits the industrial production of zeolites at a large scale because of their toxicity to the environment [5]. Recently, a dry gel conversion (DGC) method has attracted widespread attention due to its advantages such as high 
zeolite yield and low environmental pollution [10,11]. However, direct synthesis of ZSM-5 zeolite without an organic template or seed crystals via dry gel conversion has rarely been reported to date.

Generally, the conventional MTA pathway consists of methanol-to-olefins (MTO) and olefins-to-aromatics (OTA) reactions [10]. In the OTA reaction, olefins need to be cyclized to cycloalkanes and then dehydrogenated to aromatics [3]. Meanwhile, the side reaction of olefins hydrogenation to alkanes is inevitable. Therefore, transitional metals such as $\mathrm{Zn}, \mathrm{Ga}, \mathrm{Ag}$, Mo, etc. are required to improve the dehydrogenation or hydrogen transfer capability of ZSM-5 and then promote the yield of aromatics in the OTA reaction [11-13]. Among all introduced metal species, $\mathrm{Zn}$ has been recognized as one of the most attractive components due to its excellent dehydrogenation ability, the high selectivity of BTX and low cost [14-16]. Ono et al. firstly reported the significant promotion of aromatic selectivity in the MTA reaction by modifying ZSM-5 zeolite with Zn metal [17]. In addition, Kolyagin et al. found that three types of zinc species were involved in $\mathrm{Zn} / \mathrm{HMFI}$ zeolite prepared by impregnation with an aqueous solution of $\mathrm{Zn}\left(\mathrm{NO}_{3}\right)_{2}$, i.e., small $\mathrm{ZnO}$ clusters inside the pores, large $\mathrm{ZnO}$ clusters on the external surface, and zinc cations $\left(\mathrm{Zn}^{2+}\right.$ or $\left.\mathrm{ZnOH}^{+}\right)$[18]. In particular, $\mathrm{ZnOH}^{+}$ species are reported to be the active sites to catalyze dehydrogenation or hydrogenation, which are formed by coordinating $\mathrm{Zn}^{2+}$ cations to the framework aluminate site, and serve as the Lewis (L) acid sites with medium-strong acidity [19]. Therefore, the introduction of Zn into ZSM-5 zeolite decreases the Brønsted (B) acid sites and increases the proportion of medium-strong acid sites due to the formation of $\mathrm{ZnOH}^{+}$species. Recently, the multipleoxides-modified ZSM-5 zeolites were demonstrated to be a class of efficient catalysts for selective methanol conversion to p-xylene $[20,21]$. The primary metal modification, typically the low cost and non-toxic $\mathrm{Zn}$ species, is aimed to enhance the dehydro-cyclization and MTA reactivity [22,23]. Subsequent modification with the other oxides such as $\mathrm{Mg}$ [24], P [25], Si [26], B [27], etc. not only narrows the micropore openings and thus improves the zeolite shape-selectivity, but also effectively passivates the external acidity.

As the MTA reaction progresses, bulky by-products such as polyaromatic hydrocarbons and coke are inevitably formed companied with the targeted BTX products within ZSM-5 framework. These by-products are too bulky to diffuse through the narrow micropore walls of ZSM-5 $(0.54 \mathrm{~nm})$ resulting in a deactivation and reduced catalyst life span $[28,29]$. Therefore, increasing diffusion and catalyst efficiency via developing hierarchical ZSM-5 zeolites is of significance for MTA reaction [30]. Hitherto, reported strategies for making hierarchical ZSM- 5 zeolites can be divided into constructive and destructive methods [31]. Although most of these constructive methods successfully acquire mesoporosity and improve performance in catalytic reactions, the costs and environmental issues raised by the substantial usage of templates require further evaluation for industrialization [32]. In contrast, destructive methods, including desilication and dealumination, are relatively easier to implement on an industrial scale [33]. As reported in our previous study, the introduction of mesopores by the alkaline-mediated leaching of framework $\mathrm{Si}$ has been regarded as a promising method due to the low cost and high efficiency [34]. The sequential dealumination will remove the non-framework aluminate and thereby reduce the diffusion resistance in the ZSM-5.

Herein, firstly, the pure phase ZSM-5 zeolite was directly synthesized without adding any templates and seeds via a dry gel conversion method. Secondly, the hierarchical ZSM-5 zeolites were prepared using the as-synthesized ZSM- 5 zeolite as the raw material by sequential desilication-dealumination to reduce the diffusion resistance. Then, $\mathrm{Zn}$ and $\mathrm{P}$ were introduced into the hierarchical ZSM- 5 zeolite by an impregnation method to adjust its acidity, and the differences of acid properties and MTA reaction performance between Zn modified and Zn-P co-modified ZSM-5 zeolite were compared. 


\section{Results and Discussions}

\subsection{Sample Characterizations}

The XRD patterns of ZSM-5, HZSM-5, Zn modified and Zn-P co-modified samples are presented in Figure 1. The zoom areas have been shown in Figures S1 and S2. All the samples exhibited typical diffraction peaks in the $2 \theta$ range of $8-10^{\circ}$ and $22-25^{\circ}$ corresponding to the MFI structure. For ZSM- 5 zeolite by the DGC method, low Zn and P loading cases ( $\mathrm{Zn}$ loading is less than $2.0 \mathrm{wt} \%$ and $\mathrm{P}$ loading is less $1.0 \mathrm{wt} \%$ ), intensities of the samples are not apparently changed. This indicates that the framework structure of ZSM-5 zeolites is not affected by $\mathrm{Zn}$ and P species introduction. With the increase of $\mathrm{Zn}$ loadings, the intensity of diffraction peaks is slightly decreased (Figure 1a). This may be due to deposited of amorphous $\mathrm{Zn}$ species on the surface or in the pores of hierarchical ZSM-5 zeolites [35]. In contrast, when the P loading is $1.0 \mathrm{wt} \%$, the intensity of diffraction peaks is dramatically decreased as displayed in Figure $1 \mathrm{~b}$. This is because P species exist as oxides on the surface and/or in the pores of ZSM- 5 zeolites due to the excessive treatment by the phosphoric acid solution in the impregnation method [36].

(a)

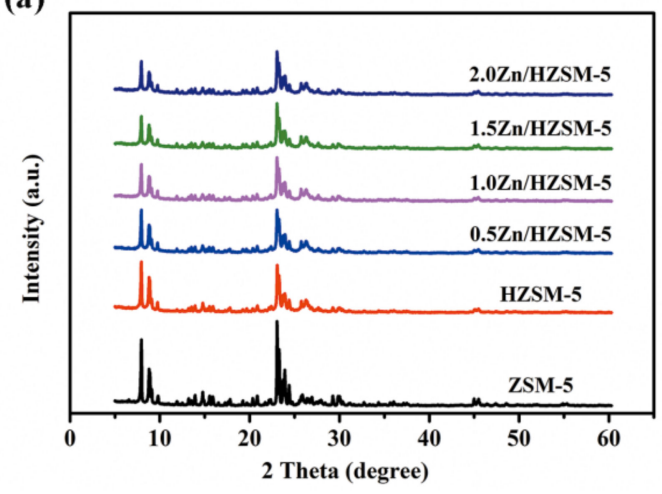

(b)

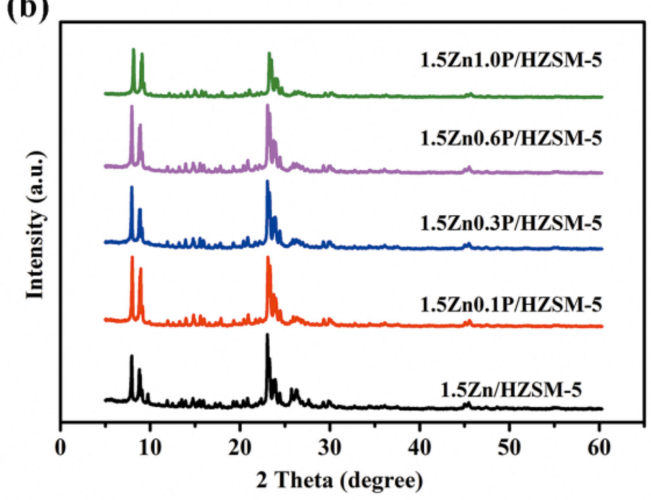

Figure 1. X-ray diffraction (XRD) patterns of ZSM-5, HZSM-5, Zn modified (a) and Zn-P co-modified (b) samples.

$\mathrm{N}_{2}$ adsorption-desorption isotherms and pore size distribution of ZSM-5, HZSM-5, Zn modified and Zn-P co-modified samples are in Figure 2. Textural properties derived from different catalysts are summarized in Table 1. ZSM-5 presents a type I isotherm indicating that there are mainly micropores existed in ZSM- 5 zeolites synthesized by the dry gel conversion method. After sequential desilication-dealumination, the BET surface area was increased from $262 \mathrm{~m}^{2} / \mathrm{g}$ to $311 \mathrm{~m}^{2} / \mathrm{g}$ in HZSM-5 zeolite as shown in Table 1 . In addition, the adsorption isotherm changed into type IV isotherm with a hysteresis loop at $\mathrm{P} / \mathrm{P}_{0}=0.4-1.0$, reflecting the mesopores in ZSM-5 zeolites introduced by sequential desilication-dealumination. Zn-modified and Zn-P co-modified samples exhibited a similar isotherm type and hysteresis loop shape compared to HZSM- 5 since introducing Zn and/or P species do not change the pore structure of synthesized HZSM-5 zeolites. With the increase of $\mathrm{Zn}$ loadings, the total surface area is slightly decreased due to $\mathrm{Zn}$ species deposited in the pores of ZSM-5 zeolites [37]. This is further proved by the pore size distribution as displayed in Figure 2a. In contrast, the BET surface area was increased after phosphorus modification, especially when the phosphorus loading was $1.0 \mathrm{wt} \%$, the BET surface area was largely increased to $363 \mathrm{~m}^{2} / \mathrm{g}$ in Table 2 . In addition, the pore size distribution was broadened, attributed to the etching effect of phosphoric acid, which is consistent with the $\mathrm{XRD}$ results. 
(a)

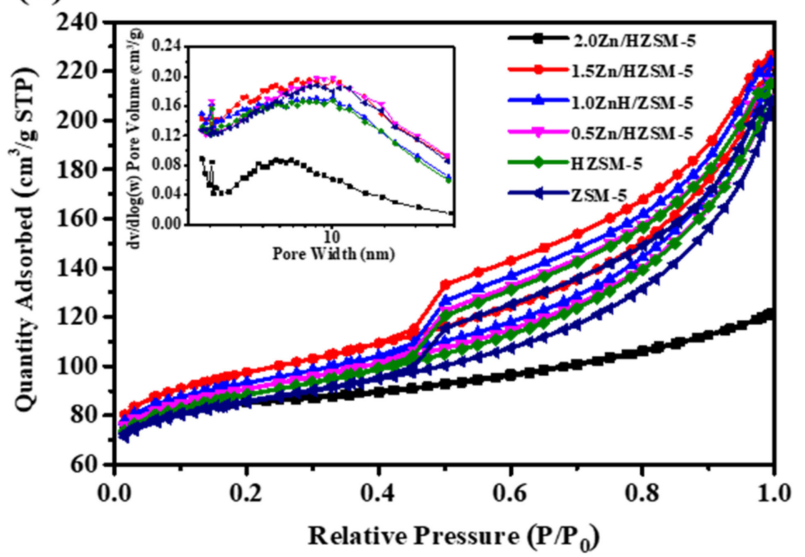

(b)

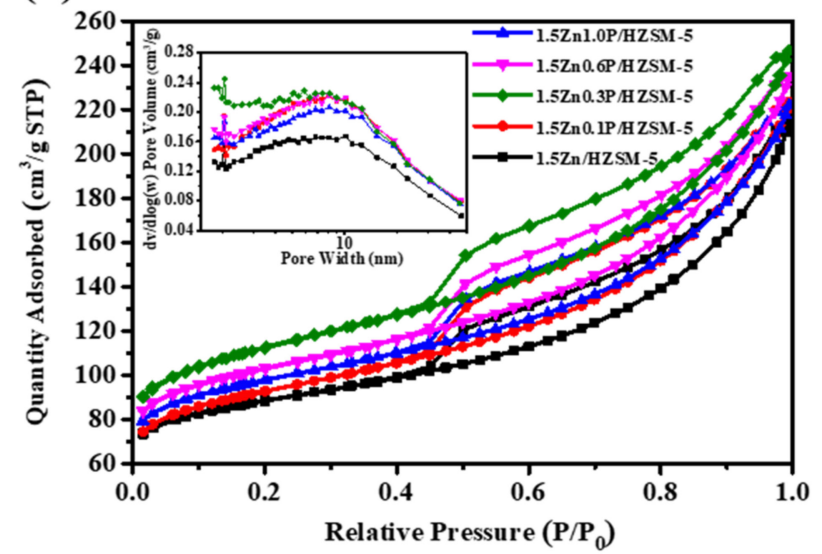

Figure 2. $\mathrm{N}_{2}$ absorption-desorption isotherms and pore size distribution (insert image) of ZSM-5, HZSM-5, Zn modified (a) and Zn-P co-modified (b) samples.

Table 1. Textural properties of ZSM-5, HZSM-5, Zn modified and Zn-P co-modified samples.

\begin{tabular}{|c|c|c|c|c|c|c|c|}
\hline & $\begin{array}{c}\text { Relative } \\
\text { Crystallinity }\end{array}$ & $\mathrm{S}_{\mathrm{BET}}{ }^{\mathrm{a}}$ & $S_{\text {micro }}^{b}$ & $S_{\text {meso }}{ }^{c}$ & $\mathrm{~V}_{\text {total }}{ }^{b}$ & $\mathrm{~V}_{\text {micro }}{ }^{b}$ & $V_{\text {meso }}{ }^{d}$ \\
\hline & & & & & & $\left(\mathrm{cm}^{2} / \mathrm{g}\right)$ & \\
\hline ZSM-5 & $100 \%$ & 262 & 206 & 56 & 0.182 & 0.108 & 0.079 \\
\hline HZSM-5 & 49.9 & 311 & 167 & 144 & 0.311 & 0.088 & 0.244 \\
\hline $0.5 \mathrm{Zn} / \mathrm{HZSM}-5$ & 52.1 & 297 & 164 & 133 & 0.302 & 0.086 & 0.238 \\
\hline $1.0 \mathrm{Zn} / \mathrm{HZSM}-5$ & 52.5 & 289 & 160 & 129 & 0.293 & 0.084 & 0.229 \\
\hline 1.5Zn/HZSM-5 & 54.8 & 282 & 154 & 128 & 0.294 & 0.081 & 0.235 \\
\hline 2.0Zn/HZSM-5 & 52.2 & 271 & 154 & 117 & 0.280 & 0.081 & 0.219 \\
\hline 1.5Zn0.1P/HZSM-5 & 50.5 & 299 & 144 & 155 & 0.312 & 0.076 & 0.258 \\
\hline 1.5Zn0.3P/HZSM-5 & 49.5 & 314 & 159 & 155 & 0.321 & 0.084 & 0.259 \\
\hline 1.5Zn0.6P/HZSM-5 & 49.5 & 332 & 167 & 163 & 0.329 & 0.088 & 0.262 \\
\hline 1.5Zn1.0P/HZSM-5 & 32.2 & 363 & 169 & 194 & 0.348 & 0.089 & 0.277 \\
\hline
\end{tabular}

${ }^{a}$ BET surface area. ${ }^{b}$ Calculated by t-plot method. ${ }^{c} S_{\text {meso }}=S_{\text {BET }}-S_{\text {micro. }}{ }^{d}$ Calculated by BJH adsorption data.

Table 2. Acid amounts of Zn modified and Zn-P co-modified samples.

\begin{tabular}{|c|c|c|c|c|c|c|c|}
\hline \multirow{2}{*}{ Samples } & \multicolumn{3}{|c|}{ Py-IR $(\mu \mathrm{mol} / \mathrm{g})$} & \multicolumn{4}{|c|}{$\mathrm{NH}_{3}-\mathrm{TPD}(\mu \mathrm{mol} / \mathrm{g})$} \\
\hline & Brønsted $^{a}$ & Lewis $^{a}$ & $\mathbf{L} / \mathbf{B}^{\mathbf{b}}$ & Total $^{c}$ & Strong $\mathrm{d}$ & Medium $^{d}$ & Weak $^{d}$ \\
\hline HZSM-5 & 262 & 114 & 0.44 & 761.6 & 212.7 & 174.3 & 374.7 \\
\hline $0.5 \mathrm{Zn} / \mathrm{HZSM}-5$ & 246 & 204 & 0.83 & 807.1 & 180.9 & 223.8 & 402.4 \\
\hline $1.0 \mathrm{Zn} / \mathrm{HZSM}-5$ & 164 & 222 & 1.35 & 799.3 & 173.5 & 240.1 & 385.7 \\
\hline $1.5 \mathrm{Zn} / \mathrm{HZSM}-5$ & 161 & 252 & 1.57 & 816.5 & 177.3 & 245.2 & 394.0 \\
\hline 2.0Zn/HZSM-5 & 159 & 278 & 1.75 & 818 & 152.6 & 257.9 & 407.5 \\
\hline 1.5Zn0.1P/HZSM-5 & 153 & 303 & 1.98 & 834.3 & 173.3 & 254.3 & 406.7 \\
\hline 1.5Zn0.3P/HZSM-5 & 146 & 319 & 2.19 & 966.2 & 244.9 & 266.2 & 455 \\
\hline 1.5Zn0.6P/HZSM-5 & 141 & 300 & 2.13 & 846.2 & 180.4 & 223.4 & 442.4 \\
\hline 1.5Zn1.0P/HZSM-5 & 134 & 284 & 2.12 & 782.7 & 175.1 & 208.9 & 398.7 \\
\hline
\end{tabular}

${ }^{a}$ Determined by Py-IR. ${ }^{b}$ The ratio of Lewis acid amount to Brønsted acid amount. ${ }^{c}$ Determined by $\mathrm{NH}_{3}$-TPD. ${ }^{\mathrm{d}}$ Calculated by integrating the $\mathrm{NH}_{3}$-TPD profiles in different temperature intervals.

Morphologies of ZSM-5, HZSM-5 and Zn-modified HZSM-5 zeolites were characterized by TEM (Figure 3). ZSM-5 zeolites directly synthesized by the dry gel conversion method (ZSM-5) exhibited a rectangular or hexagonal structure with a smooth surface as shown in Figure S3. After sequential desilication-dealumination, HZSM-5 zeolites can still maintain the original morphologies due to the post-treatment just slightly affecting the 
external surface of zeolites. In addition, an obvious mesoporous structure in HZSM- 5 can be observed in Figure 3b. After the introduction of Zn species into hierarchical ZSM-5 zeolites, all the catalysts exhibited a similar morphology with intercrystalline mesopores. No obvious Zn particles are aggregated on the surface of HZSM- 5 zeolites indicating a good dispersion of $\mathrm{Zn}$ species, which is in agreement with the XRD results.
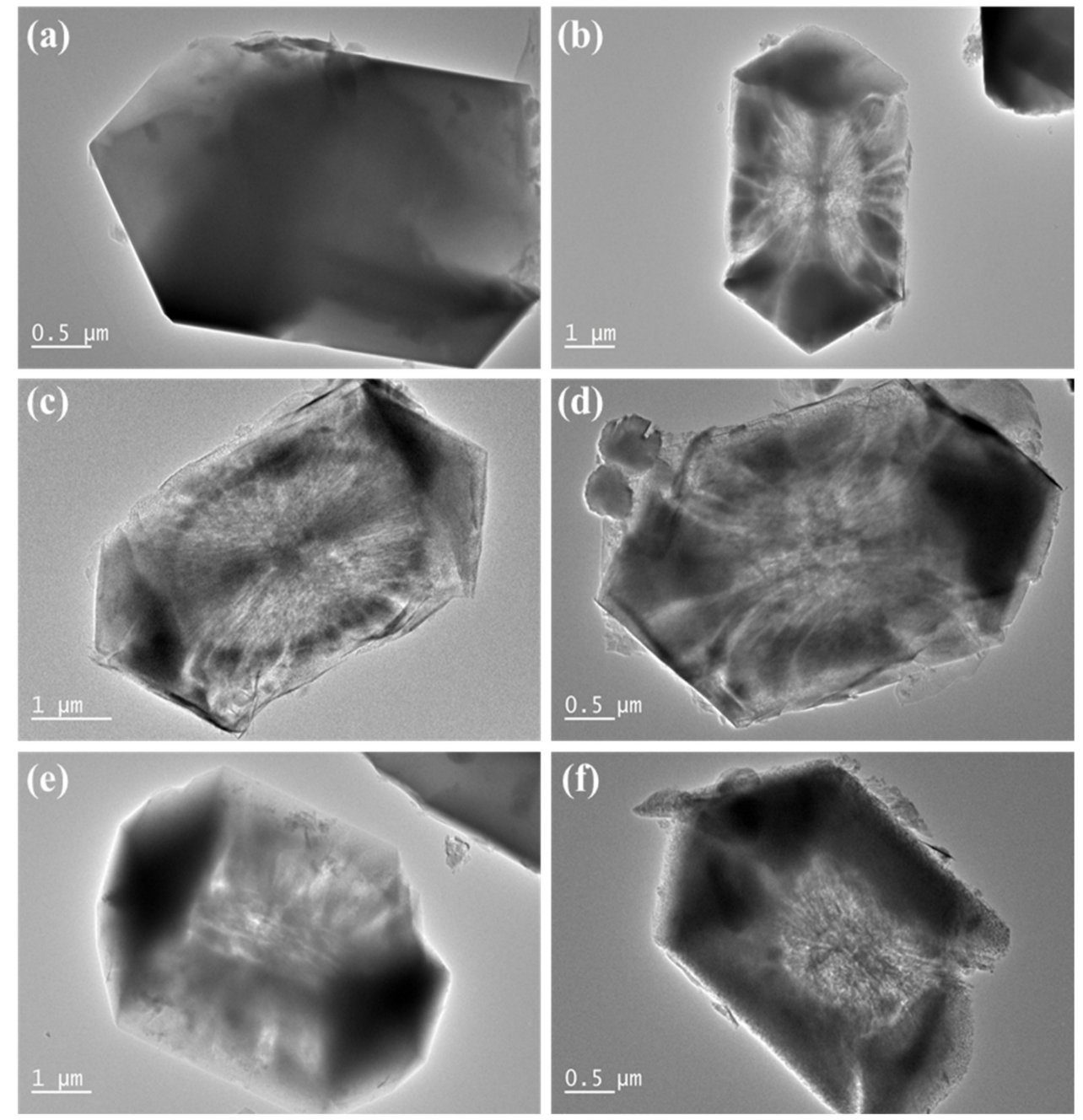

Figure 3. TEM images of $\mathrm{Zn}$ modified sample

(a) ZSM-5

(b) HZSM-5, (c) 0.5Zn/HZSM-5

(d) $1.0 \mathrm{Zn} / \mathrm{HZSM}-5$,

(e) $1.5 \mathrm{Zn} / \mathrm{HZSM}-5$, (f) $2.0 \mathrm{Zn} / \mathrm{HZSM}-5$.

The TEM images and EDX mappings of Zn-P co-modified samples are shown in Figure 4. It is found that the morphology of Zn-P co-modified samples still maintains a similar structure to the HZSM- 5 and obvious intercrystalline mesopores can be observed in Figure 4 . With the increase of $\mathrm{P}$ loadings, the mesoporous structure was enhanced as shown in Figure $4 \mathrm{~d}$. This is consistent with the XRD results that the intensity was decreased when the $\mathrm{P}$ loading is $1.0 \mathrm{wt} \%$. In addition, no particles belonging to zinc oxide or phosphorus oxide in TEM images indicating that $\mathrm{Zn}$ and $\mathrm{P}$ exhibited a good dispersion in HZSM-5 zeolites and the introduction of $\mathrm{P}$ species did not cause $\mathrm{Zn}$ species to fall off. 

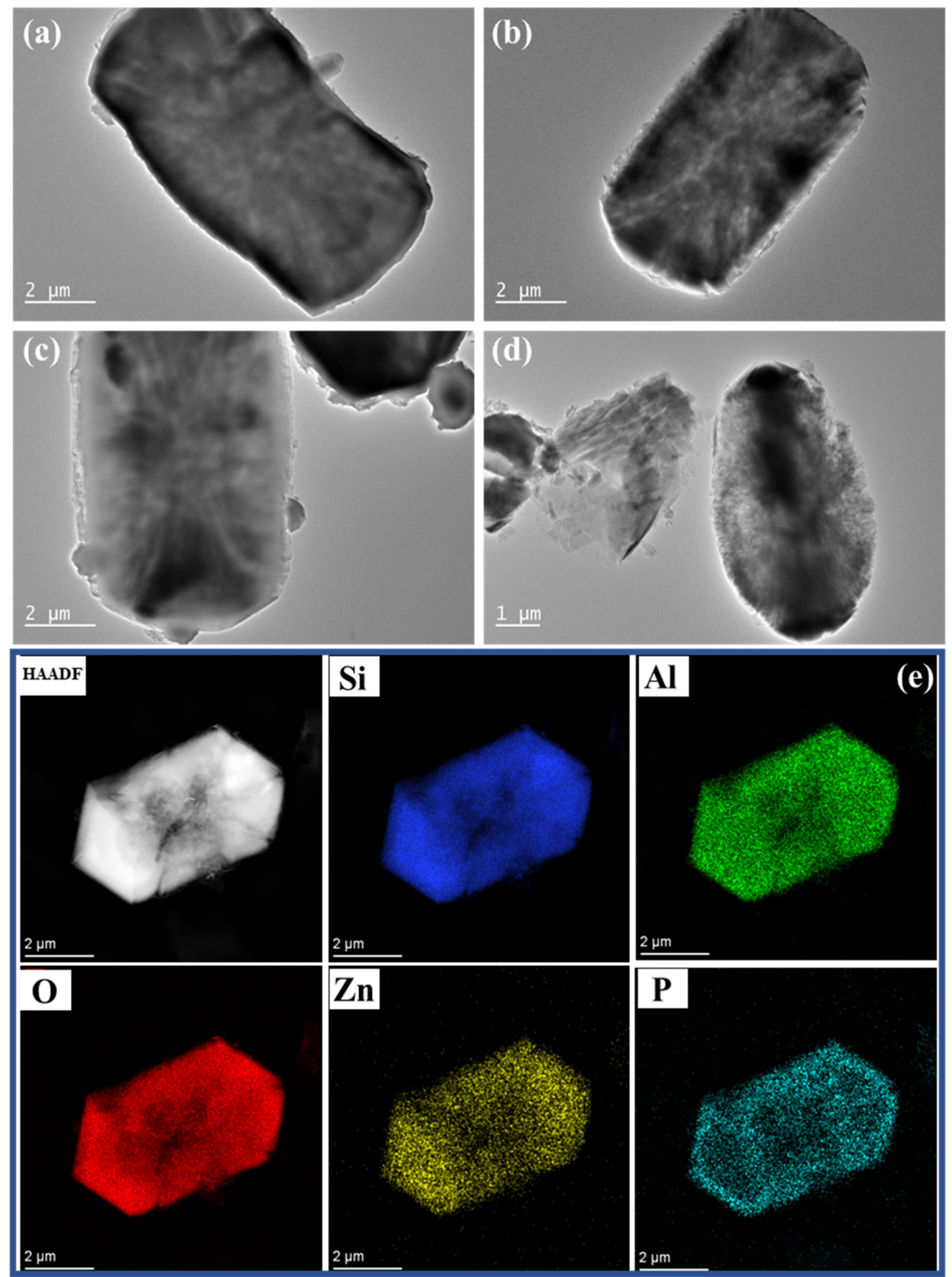

Figure 4. TEM images and energy-dispersive X-ray spectroscopy (EDX) mappings of Zn-P co-modified samples: (a) 1.5Zn0.1P/HZSM-5, (b) 1.5Zn0.3P/HZSM-5, (c) 1.5Zn0.6P/HZSM-5, (d) 1.5Zn1.0P/HZSM-5, (e) high angle annular dark-field (HAADF) and EDX mappings of 1.5Zn0.3P/HZSM-5.

Figure $5 \mathrm{a}, \mathrm{b}$ show the UV-vis spectra of the $\mathrm{Zn}$-modified and Zn-P co-modified catalysts. Both two absorption bands at $207 \mathrm{~nm}\left(\mathrm{ZnOH}^{+}\right.$species caused by the interaction of $\mathrm{Zn}$ species and framework $\mathrm{O}^{2-}$ ) and $275 \mathrm{~nm}$ (the $\mathrm{ZnO}$ cluster around $1 \mathrm{~nm}$ ) appears in all the $\mathrm{Zn}$-modified and $\mathrm{Zn}-\mathrm{P}$ co-modified samples, indicating the coexistence of $\mathrm{ZnOH}^{+}$and $\mathrm{ZnO}$ clusters in the synthesized samples $[37,38]$. The chemical state of the $\mathrm{Zn}$ species on the surface of the zeolite was determined by X-ray photoelectron spectroscopy (XPS) 
analysis in Figure 5c. Peaks shown at $1023.3 \mathrm{eV}$ and $1024.2 \mathrm{eV}$ should be attributed to $\mathrm{ZnO}$ and $\mathrm{ZnOH}^{+}$species, respectively [39]. The portion of surface $\mathrm{ZnOH}^{+}$species in $1.5 \mathrm{Zn} 0.3 \mathrm{P} / \mathrm{HZSM}-5$ (about $60 \%$ ) is higher than that of $1.5 \mathrm{Zn} / \mathrm{HZSM}-5$ (about $53 \%$ ), indicating that the introduction of $\mathrm{P}$ species will further enhance the distribution of $\mathrm{Zn}$ species.
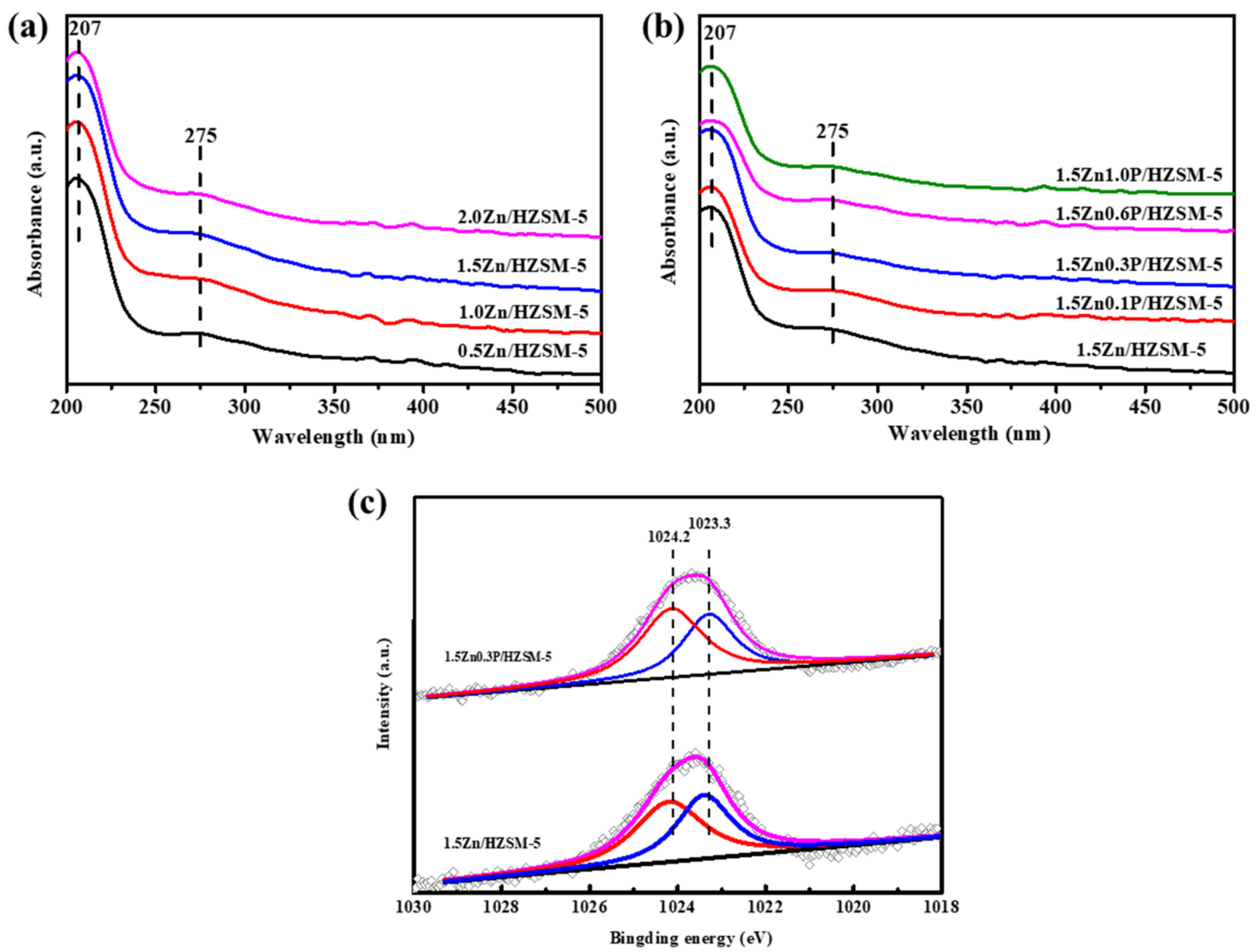

Figure 5. Ultraviolet-visible (UV-vis) spectra of Zn modified (a) and Zn-P co-modified (b) samples and X-ray photoelectron spectroscopy (XPS) spectra of Zn $2 \mathrm{P}_{3 / 2}$ for 1.5Zn/HZSM-5 and 1.5Zn0.3P/HZSM-5 (c).

The type and concentration of Brønsted and Lewis acid sites for Zn-modified and Zn-P co-modified samples were determined by Fourier-transformed infrared spectrum of pyridine adsorption (Py-IR) characterization and the results are shown in Figure 6a,b, respectively. The detailed acid amounts and acid distributions are summarized in Table 2. Vibration peaks at 1547 and $1454 \mathrm{~cm}^{-1}$ are assigned as the adsorption of pyridine on Brønsted and Lewis acid sites, respectively, while the vibration peaks at $1490 \mathrm{~cm}^{-1}$ are results of the co-effects of both Brønsted and Lewis acid sites [38]. Compared to the hierarchical ZSM-5 zeolite (HZSM-5), the total acid amount was slightly changed after the Zn modification. With the increase of $\mathrm{Zn}$ loadings, the intensity of Brønsted acid was decreased, while the intensity of Lewis acid was increased as shown in Figure 6a. Thus, the ratio of Lewis acid to Brønsted acid was largely increased from 0.44 of HZSM- 5 to 1.75 of $2.0 \mathrm{Zn} / \mathrm{HZSM}-5$ in Table 2 . This indicates that the introduced Zn species covered the Brønsted acid sites firstly, and then interacted with Brønsted acid sites to generate new Lewis acid sites [3]. Compared to the $\mathrm{Zn}$ modified samples, the intensity of Brønsted acid was further decreased, while the intensity of Lewis acid was increased firstly and then decreased with the increase of $\mathrm{P}$ loadings as shown in Figure 6b. Therefore, the ratio of Lewis acid to Brønsted acid was firstly increased from 1.57 of $1.5 \mathrm{Zn} / \mathrm{HZSM}-5$ to 2.19 of $1.5 \mathrm{Zn} 0.3 \mathrm{P} / \mathrm{HZSM}-5$ and then decreased to 2.12 of $1.5 \mathrm{Zn} 1.0 \mathrm{P} / \mathrm{HZSM}-5$ in Table 2. Therefore, the introduction of P species 
leads to two consequences: (1) exclusively poisoning the Brønsted acid sites; (2) promoting the $\mathrm{Zn}$ species dispersion and generating more $\mathrm{Zn}$-Lewis acid sites [25].

(a)

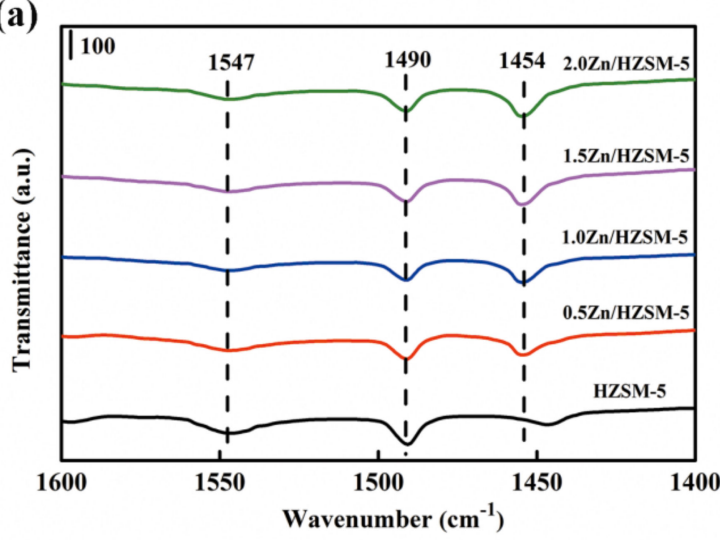

(c)

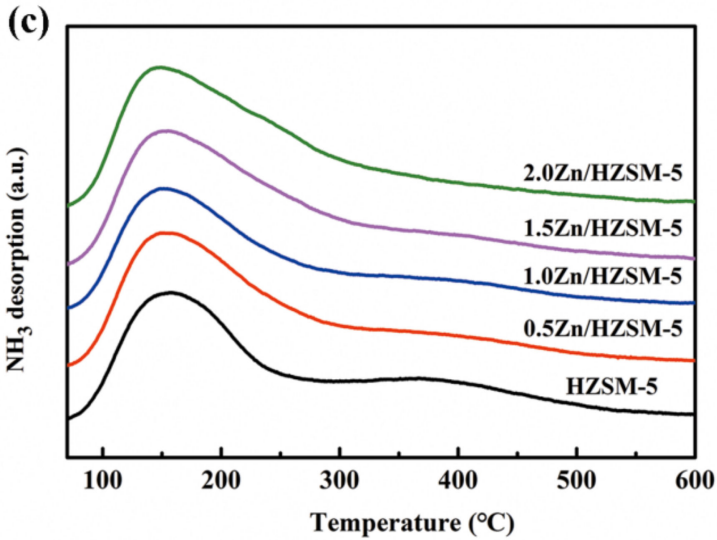

(b)

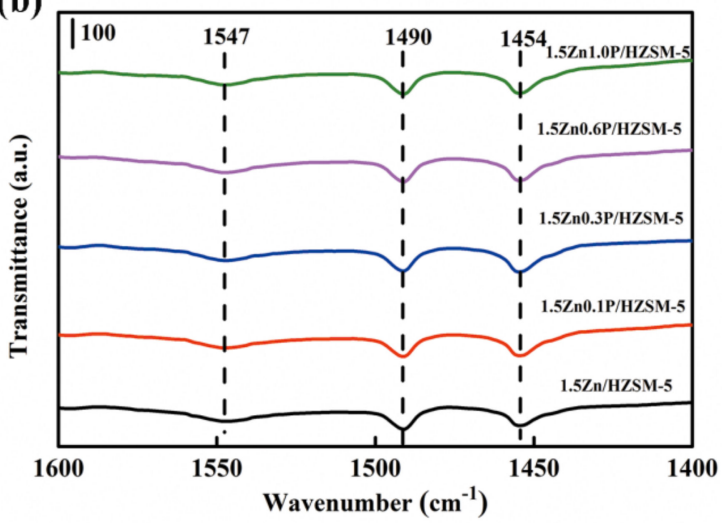

(d)

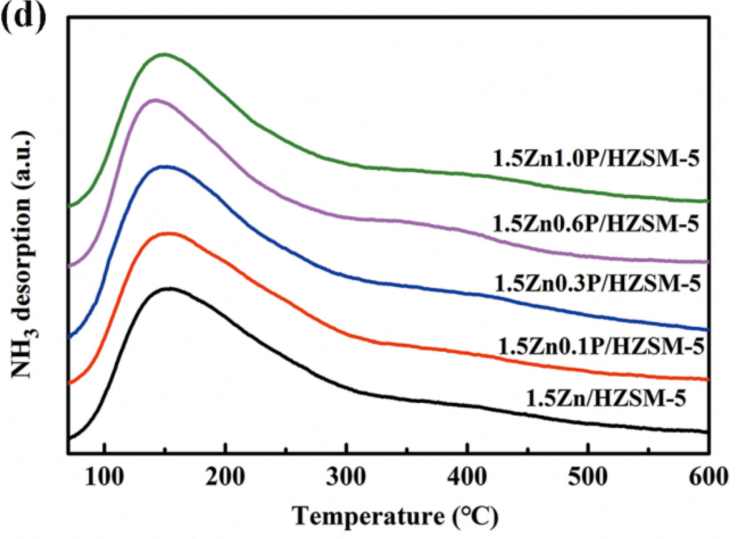

Figure 6. Fourier-transformed infrared spectrum of pyridine adsorption (Py-IR) spectra ((a) Zn modified, (b) Zn-P comodified) and $\mathrm{NH}_{3}$-TPD profiles ((c) Zn modified, (d) Zn-P co-modified) of catalysts.

The acid properties of the samples were measured by $\mathrm{NH}_{3}-\mathrm{TPD}$, and the results are shown in Figure $6 \mathrm{c}, \mathrm{d}$. The desorption peaks in $\mathrm{NH}_{3}$-TPD profiles consist of lowtemperature peaks $\left(100-300{ }^{\circ} \mathrm{C}\right)$ and high-temperature peaks $\left(300-550{ }^{\circ} \mathrm{C}\right)$. For lowtemperature peaks, it represents weak acid sites $\left(120-200{ }^{\circ} \mathrm{C}\right)$ and medium acid sites $\left(200-300{ }^{\circ} \mathrm{C}\right)[3]$, while the high-temperature peaks $\left(300-550^{\circ} \mathrm{C}\right)$ correspond to the strong acid sites. It is found that the intensity of strong acid sites was dramatically decreased, while the intensity of weak and medium acid sites was increased and expanded towards the high temperatures. As shown in Table 2, the amount of strong acid was decreased from $212.7 \mu \mathrm{mol} / \mathrm{g}$ of HZSM-5 to $152.6 \mu \mathrm{mol} / \mathrm{g}$ of $2.0 \mathrm{Zn} / \mathrm{HZSM}-5$, while the amounts of weak and medium acid were increased from $374.7 \mu \mathrm{mol} / \mathrm{g}$ and $174.3 \mu \mathrm{mol} / \mathrm{g}$ of HZSM5 to $407.5 \mu \mathrm{mol} / \mathrm{g}$ and $257.9 \mu \mathrm{mol} / \mathrm{g}$ of $2.0 \mathrm{Zn} / \mathrm{HZSM}-5$, respectively. The generated weak and medium acid sites are attributed to the interaction between the introduced $\mathrm{Zn}$ species and strong acid sites. With the increasing amount of $P$ species into the zeolites, the amounts of weak, medium and strong acid sites were increased firstly and then decreased (Figure $6 \mathrm{~d}$ and Table 2) because a small amount of $P$ modification enhances the distribution of $\mathrm{Zn}$ species in zeolites and generates more $\mathrm{Zn}$-Lewis acid sites, while a large amount of $\mathrm{P}$ modification covers the acid site in zeolites.

\subsection{Catalytic Performance in Methanol to Aromatics (MTA) Reaction}

The catalytic performance of ZSM-5, HZSM-5, Zn modified and Zn-P co-modified samples was evaluated in the MTA reaction, and the distribution of aromatic products is shown in Figure 7a,b. The detailed product distribution is summarized in Table 3. The 
selectivity of BTX and aromatics of ZSM- 5 was $20.59 \%$ and $29.41 \%$, respectively. After introducing hierarchical pores into ZSM-5 zeolites via the post-treatment method, the selectivity of BTX was decreased from $20.59 \%$ to $18.03 \%$. The selectivity of aromatics was increased from $29.41 \%$ to $30.56 \%$, which agrees with the increase of $\mathrm{C}_{9}{ }^{+}$from $8.82 \%$ to $12.53 \%$ in Table 3 . The introduction of a large number of mesopores after sequential desilication-dealumination provides space for the further reaction of macromolecular products, resulting in a decrease in the selectivity of light aromatics and a significant increase in the selectivity of $\mathrm{C}_{9}{ }^{+}$.

(a)

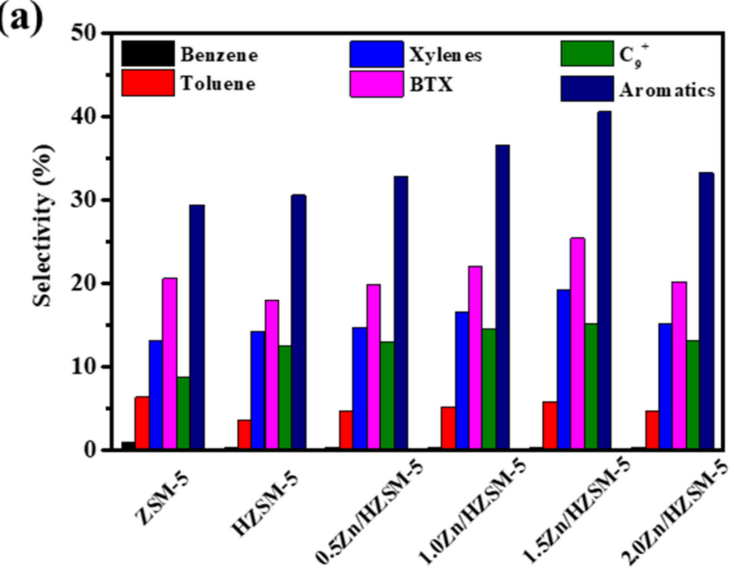

(c)

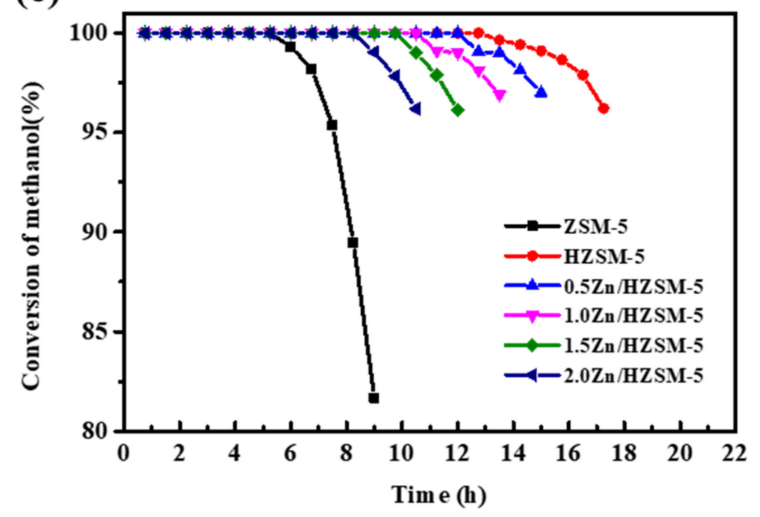

(b)

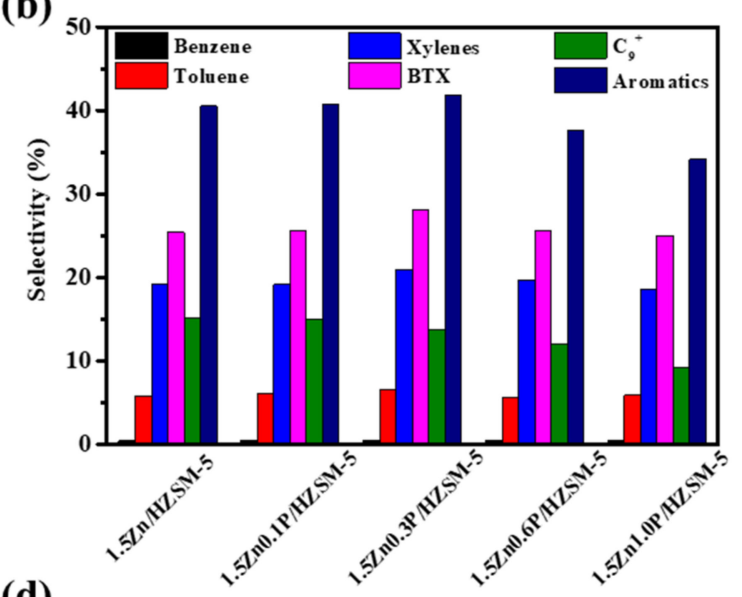

(d)

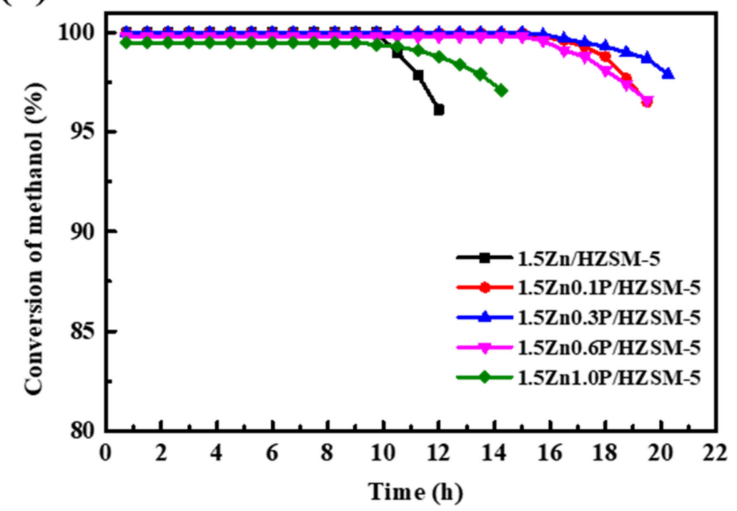

Figure 7. Aromatic product distribution (a,b) and conversion of methanol versus time (c,d) over ZSM-5, HZSM-5, Zn modified and Zn-P co-modified samples.

After the HZSM-5 zeolites were modified with Zn species, the selectivity of BTX and aromatics was largely increased when the $\mathrm{Zn}$ loadings were $0.5 \mathrm{wt} \%, 1 \mathrm{wt} \%$ and $1.5 \mathrm{wt} \%$ as shown in Figure 7a. This is because the introduction of $\mathrm{Zn}$ species interacts with the Brønsted acid sites and generates dehydrogenation sites, which improved the efficiency of the dehydrogenation step in the aromatization process resulting in an increase in aromatic selectivity. Thus, 1.5Zn/HZSM-5 reached the highest selectivity of BTX $(25.40 \%)$ and aromatics $(15.11 \%)$. By further increasing Zn loading to $2.0 \mathrm{wt} \%$, the selectivity of BTX and aromatics was decreased to $20.19 \%$ and $13.04 \%$, respectively. It is inferred that only introducing appropriate Zn species into ZSM- 5 zeolites generates enough Brønsted acid sites to ensure the processes of dehydration, cyclization and aromatization. At the same time, the $\mathrm{Zn}$ species can also provide enough $\mathrm{Zn}(\mathrm{OH})^{+}$active sites for dehydrogenation. However, if a large amount of $\mathrm{Zn}$ species is introduced into ZSM-5 zeolites, Brønsted acid sites are reduced and the process of methanol dehydration to produce dimethyl ether is retarded. Therefore, the steps of olefin cyclization and aromatization will be affected, resulting in a decrease in aromatic selectivity. 
Table 3. Distribution of methanol to aromatics (MTA) products over Zn modified and Zn-P co-modified samples.

\begin{tabular}{ccccccc}
\hline Sample & B (\%) & T (\%) & X (\%) & BTX (\%) & C $_{\mathbf{9}}^{+}$(\%) & Aromatics (\%) \\
\hline ZSM-5 & 1.01 & 6.41 & 13.17 & 20.59 & 8.82 & 29.41 \\
HZSM-5 & 0.25 & 3.59 & 14.19 & 18.03 & 12.53 & 30.56 \\
0.5Zn/HZSM-5 & 0.36 & 4.72 & 14.75 & 19.83 & 13.02 & 32.85 \\
1.0Zn/HZSM-5 & 0.32 & 5.17 & 16.57 & 22.06 & 14.49 & 36.55 \\
1.5Zn/HZSM-5 & 0.39 & 5.84 & 19.17 & 25.40 & 15.11 & 40.51 \\
2.0Zn/HZSM-5 & 0.29 & 4.75 & 15.15 & 20.19 & 13.04 & 33.23 \\
1.5Zn0.1P/HZSM-5 & 0.47 & 6.03 & 19.15 & 25.65 & 15.04 & 40.69 \\
1.5Zn0.3P/HZSM-5 & 0.53 & 6.62 & 20.97 & 28.12 & 13.76 & 41.88 \\
1.5Zn0.6P/HZSM-5 & 0.49 & 5.56 & 19.61 & 25.66 & 11.97 & 37.63 \\
1.5Zn1.0P/HZSM-5 & 0.50 & 5.87 & 18.62 & 24.99 & 9.13 & 34.12 \\
\hline
\end{tabular}

After Zn, P co-modification, the aromatic product distribution of ZSM-5 zeolites exhibited a huge difference as shown in Figure $7 \mathrm{~b}$. For example, compared to $\mathrm{Zn}$ modified ZSM- 5 zeolites, the selectivity of BTX and aromatics of Zn, P co-modified ZSM- 5 zeolites increase firstly and then decrease, while the selectivity of $\mathrm{C}_{9}{ }^{+}$was decreased with the increase of P loadings. When the P loading is $0.3 \mathrm{wt} \%$, the selectivity of BTX is increased from $25.4 \%$ of $1.5 \mathrm{Zn} / \mathrm{HZSM}-5$ to $28.12 \%$ of $1.5 \mathrm{Zn} 0.3 \mathrm{P} / \mathrm{HZSM}-5$. This phenomenon should be contributed to two reasons: (1) the introduction of $\mathrm{P}$ species reduces the amount of Brønsted acid sites, retards the further reaction of light aromatics, and reduces the selectivity of $\mathrm{C}_{9}{ }^{+}$; (2) the introduction of $\mathrm{P}$ species will promote the dispersion of $\mathrm{Zn}$ species and part of $\mathrm{P}$ species will exist as the phosphorus oxide deposited on the pores of ZSM-5 zeolites. An appropriate amount of introduced P species into the Zn modified ZSM-5 zeolites can lead to a synergistic effect with $\mathrm{Zn}$ species. However, excessive phosphorus species into $\mathrm{Zn}$ modified ZSM-5 zeolites can dramatically decrease the amount of Brønsted acid sites and sequentially reduce the selectivity of aromatics and BTX.

Figure 7c,d show the conversion of methanol versus time over ZSM-5, HZSM-5, Zn modified and Zn-P co-modified samples. It is found that ZSM- 5 exhibited a short lifetime of $6 \mathrm{~h}$ due to the large crystal size and narrow microporous channels, which led to coke deposition after multiple reactions [39]. The lifetime of hierarchical ZSM-5 zeolites was dramatically increased to $14 \mathrm{~h}$ due to a large amount of mesopores being introduced by sequential desilication-dealumination and the diffusion properties were enhanced. However, after introducing Zn species into hierarchical ZSM-5 zeolites, the lifetime was decreased as shown in Figure 7c, which is attributed to the following two aspects. On the one hand, the introduction of $\mathrm{Zn}$ species will enhance the dehydrogenation capacity of catalysts, promote the formation of macromolecular aromatics, and aggravate the coke deposition in the pores of ZSM- 5 zeolites. The coke not only blocks the pores of ZSM-5 zeolites but also covers the active sites, resulting in the unable interaction between reactants and acid sites; on the other hand, the introduced $\mathrm{Zn}$ species exist in the form of oxides on the surface and in the pores of ZSM- 5 zeolites, which retard the diffusion properties of the catalysts.

Compared to the Zn modified ZSM-5 zeolites, the lifetime of Zn-P co-modified ZSM-5 zeolites was improved as shown in Figure $7 \mathrm{~d}$. For example, the lifetime was increased from $11 \mathrm{~h}$ of $1.5 \mathrm{Zn} / \mathrm{HZSM}-5$ to $18 \mathrm{~h}$ of $1.5 \mathrm{Zn} 0.3 \mathrm{P} / \mathrm{HZSM}-5$. Three reasons are responsible for the enhanced lifetime. Firstly, the amount of Brønsted acid sites was decreased after Zn-P co-modification, which retards the coke formation during the catalytic reaction. Secondly, the specific surface area and pore volume were increased due to the etching effect of phosphoric acid. The diffusion properties and anti-coking abilities were increased. Thirdly, the presence of $P$ species can stabilize the framework aluminate of zeolites and improve the hydrothermal stability of the catalysts [21]. Therefore, the Zn-P co-modified ZSM-5 zeolites exhibited a much longer lifetime. 


\section{Materials and Methods}

\subsection{Catalyst Preparation}

\subsubsection{The Preparation of ZSM-5 Zeolites via Dry Gel Conversion (DGC)}

Commercial basic silica sol (Qingdao Haiyang Co., Ltd., Qingdao, China, $30 \mathrm{wt} \% \mathrm{SiO}_{2}$ ) and sodium aluminate (Sinopharm Co., Ltd., Beijing, China, $41 \mathrm{wt} \% \mathrm{Al}_{2} \mathrm{O}_{3}$ ) were adopted as silicon source and aluminate source, respectively, without further treatment. A typical direct synthesis process of ZSM- 5 zeolite by dry gel conversion is as follows: $1.025 \mathrm{~g}$ of sodium aluminate and $1.675 \mathrm{~g}$ sodium hydroxide were added to $100 \mathrm{~mL}$ deionized water at room temperature and stirred for $0.5 \mathrm{~h}$. After that, $50 \mathrm{~g}$ silica sol was dropped into the mixture and continuously stirred for $6 \mathrm{~h}$. The mixture obtained was dried at $110{ }^{\circ} \mathrm{C}$ to form a dry gel and then put into $250 \mathrm{~mL}$ reactor partition. $25 \mathrm{~mL}$ deionized water was added to the bottom of a stainless-steel autoclave and put into the oven at $170{ }^{\circ} \mathrm{C}$ for $48 \mathrm{~h}$. The crystallized products were ion-exchanged three times in $1 \mathrm{~mol} / \mathrm{L} \mathrm{NH}_{4} \mathrm{Cl}$ solution $(0.1 \mathrm{~g}$ $\mathrm{ZSM}-5 / \mathrm{mL} \mathrm{NH}_{4} \mathrm{Cl}$ solution) and calcined at $550{ }^{\circ} \mathrm{C}$ for $4 \mathrm{~h}$ to obtain H-type ZSM-5 zeolites (ZSM-5).

\subsubsection{The Preparation of Hierarchical ZSM-5 Zeolites via the Destructive Method}

Typically, $1 \mathrm{~g}$ of H-type ZSM- 5 zeolites are dissolved in $10 \mathrm{~mL} 0.6 \mathrm{~mol} / \mathrm{L}$ aqueous $\mathrm{NaOH}$ solution $\left(0.1 \mathrm{~g} \mathrm{ZSM}-5 / \mathrm{mL} \mathrm{NaOH}\right.$ solution) and stirred at $80^{\circ} \mathrm{C}$ for $1 \mathrm{~h}$. Then the product was collected by filtration followed by washing with deionized water and drying at $80^{\circ} \mathrm{C}$ overnight. The alkali-treated zeolites were transferred into $0.1 \mathrm{~mol} / \mathrm{L} \mathrm{HCl}$ aqueous solution ( $5 \mathrm{~g}$ zeolite per $50 \mathrm{~mL}$ of solution) and reacted for $5 \mathrm{~h}$ at $80^{\circ} \mathrm{C}$, followed by filtration, washing with deionized water and finally dried at $80^{\circ} \mathrm{C}$ overnight. The obtained zeolites were ion-exchanged three times in $1 \mathrm{~mol} / \mathrm{L} \mathrm{NH}_{4} \mathrm{Cl}$ solution and calcined at $550{ }^{\circ} \mathrm{C}$ for $4 \mathrm{~h}$ to obtain H-type hierarchical ZSM-5 zeolites (HZSM5).

3.1.3. The Preparation of Zn-Modified or Zn-P Co-Modified Hierarchical ZSM-5 Zeolites via Impregnation Method

The Zn-modified or Zn-P co-modified hierarchical ZSM-5 zeolites were prepared by the wet impregnation method. Typically, a predetermined amount of $\mathrm{Zn}\left(\mathrm{NO}_{3}\right)_{2}$ and phosphoric acid was dissolved in the deionized water and then added into the synthesized hierarchical ZSM- 5 zeolites. The mixture was stirred for $24 \mathrm{~h}$ at room temperature, followed by drying at $110{ }^{\circ} \mathrm{C}$ overnight and calcination at $550{ }^{\circ} \mathrm{C}$ for $4 \mathrm{~h}$ in a muffle furnace. The obtained products were designated as $x Z n / H Z S M-5$ or $x Z n y P / H Z S M-5$ ( $x$ and $y$ are the weight percentages of introduced $\mathrm{Zn}$ and $\mathrm{P}$ species, respectively).

\subsection{Characterization}

Phases of synthesized zeolites were characterized by the X'Pert Pro MPD polycrystalline powder X-ray diffractometer (XRD, PANalytical) with $\mathrm{Cu} \mathrm{K \alpha}$ radiation at $40 \mathrm{kV}$ and $400 \mathrm{~mA}$. The data was collected when the 2 Theta ranging from $5-60^{\circ}$ and the scanning speed was $10^{\circ} / \mathrm{min}$. The $\mathrm{N}_{2}$ adsorption-desorption isotherms were measured at $-196^{\circ} \mathrm{C}$ using a Micromeritics Tristar 3020 physical adsorption instrument. The total surface area and micropore volume were calculated using Brunauer-Emmett-Teller (BET) equation and t-plot method, respectively. The Barrett-Joyner-Halenda (BJH) method was used to determine the mesopore volume and pore size distribution. The morphology was investigated by a transmission electron microscope (TEM, JEM-2100UHR). The samples were ultrasonically dispersed in absolute ethanol and dropped cast on carbon-coated $\mathrm{Cu}$ grids. High-angle annular dark-field (HAADF) images were carried out using a scanning transmission electron microspore (STEM, FEI Titan3 Themis 300) operating at $300 \mathrm{kV}$ with FEI Super-X 4-detector EDX system. Temperature-programmed desorption of ammonia ( $\mathrm{NH}_{3}$-TPD) was conducted by an AutoChem II 2920 (Micromeritics). Typically, $100 \mathrm{mg}$ of samples were pretreated at $550{ }^{\circ} \mathrm{C}$ for $30 \mathrm{~min}$ in $\mathrm{He}$, and then $\mathrm{NH}_{3}$ was injected at $80{ }^{\circ} \mathrm{C}$ for $40 \mathrm{~min}$. After that, the reactor was purged by He at the same temperature for 60 min. Desorption of $\mathrm{NH}_{3}$ was conducted at a temperature window ranging from 70 
to $650{ }^{\circ} \mathrm{C}$ at a rate of $10{ }^{\circ} \mathrm{C} / \mathrm{min}$. A Thermo Nicolet NEXUS spectrometer was used for the Fourier-transformed infrared spectrum of pyridine adsorption (Py-IR). Firstly, all the samples were dried in a vacuum at $300^{\circ} \mathrm{C}$ for $3 \mathrm{~h}$ before analysis and then the pyridine adsorption was conducted for $24 \mathrm{~h}$ after cooling to room temperature. Then the samples were vacuumed for $3 \mathrm{~h}$ at $150{ }^{\circ} \mathrm{C}$ to remove the physically adsorbed pyridine. The UVvisible absorption spectra were measured by a Shimadzu UV-2450 spectrophotometer. The elemental contents of samples were determined by an X-ray fluorescence spectrometer (AXIOS-Petro, PANalytical, Netherlands). X-ray photoelectron spectroscopy (XPS) was measured by a Thermo Fisher's Escalab $250 \mathrm{Xi}$ instrument, and all samples were dried and compressed before analysis.

\subsection{MTA Catalytic Tests}

$0.5 \mathrm{~g}$ of catalyst (20-40 mesh) was loaded into a fixed bed reactor (inner diameter: $10 \mathrm{~mm}$, length: $50 \mathrm{~cm}$ ) and the catalyst was fixed by the quartz. First, the catalyst was activated in $\mathrm{N}_{2}(20 \mathrm{sccm})$ at $400{ }^{\circ} \mathrm{C}$ for $1 \mathrm{~h}$. After that, methanol was injected by an injection pump with a weight hourly space velocity (WHSV) of $2.1 \mathrm{~h}^{-1}$. The reaction products were analyzed online using gas chromatograph (SCION-436GC). The selectivity of the product (Si) was calculated by Equation (1):

$$
S_{i}=\frac{(\text { mass of product } i)}{(\text { total mass in the feed })} \times 100 \%
$$

When the methanol conversion rate is less than $99 \%$, the catalyst is considered to be deactivated.

\section{Conclusions}

Using ZSM-5 zeolite directly synthesized by a dry gel conversion method without adding any template or seed crystals as the raw material, hierarchical ZSM- 5 zeolites were prepared based on the synthesized ZSM- 5 via sequential desilication-dealumination. Zn and $\mathrm{P}$ species were successfully introduced into the hierarchical ZSM- 5 zeolite by the impregnation method. The effects of $\mathrm{Zn}$ and P loadings on the physiochemical properties of hierarchical ZSM-5 zeolites and MTA reaction performance were investigated. The results show that after Zn, P co-modification, the BTX and aromatics selectivity of $1.5 \mathrm{Zn} 0.3 \mathrm{P} / \mathrm{HZSM}-5$ was significantly increased to $28.12 \%$ and $41.88 \%$, respectively. The lifetime was extended from $6 \mathrm{~h}$ of ZSM- 5 to $18 \mathrm{~h}$ of $1.5 \mathrm{Zn} 0.3 \mathrm{P} / \mathrm{HZSM}-5$. This is attributed to the introduction of $\mathrm{Zn}$ and $\mathrm{P}$ species generating more new $\mathrm{Zn}$-Lewis acid sites and the ratio of $\mathrm{Zn}(\mathrm{OH})+/ \mathrm{ZnO}$ being increased.

Supplementary Materials: The following are available online at https:/ /www.mdpi.com/article/10 .3390/catal11111388/s1, Figure S1: XRD patterns (zoom area) of ZSM-5, HZSM-5, Zn modified, Figure S2: XRD patterns (zoom area) of Zn-P co-modified samples, Figure S3: SEM image of synthesized ZSM-5.

Author Contributions: Conceptualization, Y.W. and Z.L.; Data curation, Z.L. and C.D.; Investigation, Z.L.; Methodology, Z.L., N.D., T.L. and R.W.; Project administration, Y.W.; Supervision, Y.W.; Validation, Y.W. and Z.L.; Visualization, Y.W. and H.S.; Writing-original draft, Z.L., Y.W. and H.S.; Writing-review and editing, Y.W., P.P. and H.S. All authors have read and agreed to the published version of the manuscript.

Funding: This research received no external funding.

Conflicts of Interest: The authors declare that they have no conflict of interest. 


\section{References}

1. Gao, P.; Xu, J.; Qi, G.; Wang, C.; Wang, Q.; Zhao, Y.; Zhang, Y.; Feng, N.; Zhao, X.; Li, J. A mechanistic study of methanol-toaromatics reaction over Ga-modified ZSM-5 zeolites: Understanding the dehydrogenation process. ACS Catal. 2018, 8, 9809-9820. [CrossRef]

2. Olah, G.A. Beyond oil and gas: The methanol economy. Angew. Chem. Int. Ed. 2005, 44, 2636-2639. [CrossRef]

3. Niu, X.; Gao, J.; Miao, Q.; Dong, M.; Wang, G.; Fan, W.; Qin, Z.; Wang, J. Influence of preparation method on the performance of Zn-containing HZSM-5 catalysts in methanol-to-aromatics. Microporous Mesoporous Mater. 2014, 197, 252-261. [CrossRef]

4. Kim, S.D.; Noh, S.H.; Seong, K.H.; Kim, W.J. Compositional and kinetic study on the rapid crystallization of ZSM-5 in the absence of organic template under stirring. Microporous Mesoporous Mater. 2004, 72, 185-192. [CrossRef]

5. Choi, M.; Na, K.; Kim, J.; Sakamoto, Y.; Terasaki, O.; Ryoo, R. Stable single-unit-cell nanosheets of zeolite MFI as active and long-lived catalysts. Nature 2009, 461, 246-249. [CrossRef] [PubMed]

6. Yue, M.B.; Yang, N.; Jiao, W.Q.; Wang, Y.M.; He, M.-Y. Dry-gel synthesis of shaped binderless zeolites composed of nanosized ZSM-5. Solid State Sci. 2013, 20, 1-7. [CrossRef]

7. Wu, G.; Hei, F.; Guan, N.; Li, L. Oxidative dehydrogenation of propane with nitrous oxide over Fe-MFI prepared by ion-exchange: Effect of acid post-treatments. Catal. Sci. Technol. 2013, 3, 1333-1342. [CrossRef]

8. Wu, Q.; Wang, X.; Qi, G.; Guo, Q.; Pan, S.; Meng, X.; Xu, J.; Deng, F.; Fan, F.; Feng, Z. Sustainable synthesis of zeolites without addition of both organotemplates and solvents. J. Am. Chem. Soc. 2014, 136, 4019-4025. [CrossRef] [PubMed]

9. Zhang, C.; Wu, Q.; Lei, C.; Pan, S.; Bian, C.; Wang, L.; Meng, X.; Xiao, F.-S. Solvent-free and mesoporogen-free synthesis of mesoporous aluminosilicate ZSM-5 zeolites with superior catalytic properties in the methanol-to-olefins reaction. Ind. Eng. Chem. Res. 2017, 56, 1450-1460. [CrossRef]

10. Yarulina, I.; Chowdhury, A.D.; Meirer, F.; Weckhuysen, B.M.; Gascon, J. Recent trends and fundamental insights in the methanolto-hydrocarbons process. Nat. Catal. 2018, 1, 398-411. [CrossRef]

11. Wang, N.; Qian, W.; Shen, K.; Su, C.; Wei, F. Bayberry-like ZnO/MFI zeolite as high performance methanol-to-aromatics catalyst. Chem. Commun. 2016, 52, 2011-2014. [CrossRef] [PubMed]

12. Freeman, D.; Wells, R.P.; Hutchings, G.J. Conversion of methanol to hydrocarbons over $\mathrm{Ga}_{2} \mathrm{O}_{3} / \mathrm{H}-\mathrm{ZSM}^{-5}$ and $\mathrm{Ga}_{2} \mathrm{O}_{3} / \mathrm{WO} \mathrm{O}_{3}$ catalysts. J. Catal. 2002, 205, 358-365. [CrossRef]

13. Jia, Y.; Wang, J.; Zhang, K.; Feng, W.; Liu, S.; Ding, C.; Liu, P. Promoted effect of zinc-nickel bimetallic oxides supported on HZSM-5 catalysts in aromatization of methanol. J. Energy Chem. 2017, 26, 540-548. [CrossRef]

14. Su, X.; Zan, W.; Bai, X.; Wang, G.; Wu, W. Synthesis of microscale and nanoscale ZSM-5 zeolites: Effect of particle size and acidity of Zn modified ZSM-5 zeolites on aromatization performance. Catal. Sci. Technol. 2017, 7, 1943-1952. [CrossRef]

15. Conte, M.; Lopez-Sanchez, J.A.; He, Q.; Morgan, D.J.; Ryabenkova, Y.; Bartley, J.K.; Carley, A.F.; Taylor, S.H.; Kiely, C.J.; Khalid, K. Modified zeolite ZSM-5 for the methanol to aromatics reaction. Catal. Sci. Technol. 2012, 2, 105-112. [CrossRef]

16. Gong, Q.; Fang, T.; Xie, Y.; Zhang, R.; Liu, M.; Barzagli, F.; Li, J.; Hu, Z.; Zhu, Z. High-Efficiency Conversion of Methanol to BTX Aromatics Over a Zn-Modified Nanosheet-HZSM-5 Zeolite. Ind. Eng. Chem. Res. 2021, 60, 1633-1641. [CrossRef]

17. Ono, Y.; Adachi, H.; Senoda, Y. Selective conversion of methanol into aromatic hydrocarbons over zinc-exchanged ZSM-5 zeolites. J. Chem. Soc. Faraday Trans. 1 Phys. Chem. Condens. Phases 1988, 84, 1091-1099. [CrossRef]

18. Kolyagin, Y.G.; Ordomsky, V.; Khimyak, Y.; Rebrov, A.; Fajula, F.; Ivanova, I. Initial stages of propane activation over Zn/MFI catalyst studied by in situ NMR and IR spectroscopic techniques. J. Catal. 2006, 238, 122-133. [CrossRef]

19. Pan, T.; Wu, Z.; Zhou, K. In Situ Incorporation of Zn into Hierarchical ZSM-5 Zeolites for Olefin Hydroisomerization. Ind. Eng. Chem. Res. 2020, 59, 12371-12380. [CrossRef]

20. Zhang, J.; Qian, W.; Kong, C.; Wei, F. Increasing para-xylene selectivity in making aromatics from methanol with a surfacemodified Zn/P/ZSM-5 catalyst. ACS Catal. 2015, 5, 2982-2988. [CrossRef]

21. Zhang, J.; Zhu, X.; Zhang, S.; Cheng, M.; Yu, M.; Wang, G.; Li, C. Selective production of para-xylene and light olefins from methanol over the mesostructured Zn-Mg-P/ZSM-5 catalyst. Catal. Sci. Technol. 2019, 9, 316-326. [CrossRef]

22. Miyake, K.; Hirota, Y.; Ono, K.; Uchida, Y.; Tanaka, S.; Nishiyama, N. Direct and selective conversion of methanol to para-xylene over Zn ion doped ZSM-5/silicalite-1 core-shell zeolite catalyst. J. Catal. 2016, 342, 63-66. [CrossRef]

23. Pan, D.; Song, X.; Yang, X.; Gao, L.; Wei, R.; Zhang, J.; Xiao, G. Efficient and selective conversion of methanol to para-xylene over stable $\mathrm{H}$ [Zn, Al] ZSM-5/SiO 2 composite catalyst. Appl. Catal. A Gen. 2018, 557, 15-24. [CrossRef]

24. Sotelo, J.L.; Uguina, M.A.; Valverde, J.L.; Serrano, D.P. Kinetics of toluene alkylation with methanol over magnesium-modified ZSM-5. Ind. Eng. Chem. Res. 1993, 32, 2548-2554. [CrossRef]

25. Janardhan, H.; Shanbhag, G.; Halgeri, A. Shape-selective catalysis by phosphate modified ZSM-5: Generation of new acid sites with pore narrowing. Appl. Catal. A Gen. 2014, 471, 12-18. [CrossRef]

26. Kim, J.-H.; Ishida, A.; Okajima, M.; Niwa, M. Modification of HZSM-5 by CVD of various silicon compounds and generation of para-selectivity. J. Catal. 1996, 161, 387-392. [CrossRef]

27. Xue, B.; Zhang, G.; Liu, N.; Xu, J.; Shen, Q.; Li, Y. Highly selective synthesis of para-diethylbenzene by alkylation of ethylbenzene with diethyl carbonate over boron oxide modified HZSM-5. J. Mol. Catal. A Chem. 2014, 395, 384-391. [CrossRef]

28. Ni, Y.; Zhu, W.; Liu, Z. Formaldehyde intermediate participating in the conversion of methanol to aromatics over zinc modified H-ZSM-5. J. Energy Chem. 2021, 54, 174-178. [CrossRef] 
29. Teketel, S.; Skistad, W.; Benard, S.; Olsbye, U.; Lillerud, K.P.; Beato, P.; Svelle, S. Shape selectivity in the conversion of methanol to hydrocarbons: The catalytic performance of one-dimensional 10-ring zeolites: ZSM-22, ZSM-23, ZSM-48, and EU-1. ACS Catal. 2012, 2, 26-37. [CrossRef]

30. Peng, P.; Gao, X.-H.; Yan, Z.-F.; Mintova, S. Diffusion and catalyst efficiency in hierarchical zeolite catalysts. Natl. Sci. Rev. 2020, 7, 1726-1742. [CrossRef]

31. Xue, T.; Chen, L.; Wang, Y.M.; He, M.-Y. Seed-induced synthesis of mesoporous ZSM-5 aggregates using tetrapropylammonium hydroxide as single template. Microporous Mesoporous Mater. 2012, 156, 97-105. [CrossRef]

32. Chal, R.; Gérardin, C.; Bulut, M.; van Donk, S. Overview and industrial assessment of synthesis strategies towards zeolites with mesopores. ChemCatChem 2011, 3, 67-81. [CrossRef]

33. Milina, M.; Mitchell, S.; Michels, N.-L.; Kenvin, J.; Pérez-Ramírez, J. Interdependence between porosity, acidity, and catalytic performance in hierarchical ZSM-5 zeolites prepared by post-synthetic modification. J. Catal. 2013, 308, 398-407. [CrossRef]

34. Sun, H.; Peng, P.; Wang, Y.; Li, C.; Subhan, F.; Bai, P.; Xing, W.; Zhang, Z.; Liu, Z.; Yan, Z. Preparation, scale-up and application of meso-ZSM-5 zeolite by sequential desilication-dealumination. J. Porous Mater. 2017, 24, 1513-1525. [CrossRef]

35. Sun, L.; Wang, Y.; Chen, H.; Sun, C.; Meng, F.; Gao, F.; Wang, X. Direct synthesis of hierarchical ZnZSM-5 with addition of CTAB in a seeding method and improved catalytic performance in methanol to aromatics reaction. Catal. Today 2018, 316, 91-98. [CrossRef]

36. Wang, L.; Sang, S.; Meng, S.; Zhang, Y.; Qi, Y.; Liu, Z. Direct synthesis of Zn-ZSM-5 with novel morphology. Mater. Lett. 2007, 61, 1675-1678. [CrossRef]

37. Haase, M.; Weller, H.; Henglein, A. Photochemistry and radiation chemistry of colloidal semiconductors. 23. Electron storage on zinc oxide particles and size quantization. J. Phys. Chem. 1988, 92, 482-487. [CrossRef]

38. Groen, J.C.; Moulijn, J.A.; Pérez-Ramírez, J. Decoupling mesoporosity formation and acidity modification in ZSM-5 zeolites by sequential desilication-dealumination. Microporous Mesoporous Mater. 2005, 87, 153-161. [CrossRef]

39. Lee, S.; Choi, M. Unveiling coke formation mechanism in MFI zeolites during methanol-to-hydrocarbons conversion. J. Catal. 2019, 375, 183-192. [CrossRef] 